Portland State University

PDXScholar

\title{
A Solution for Sustainable Entrepreneurship: Compostable Consumption Across Industries
}

Prithvi Chauhan

Portland State University

Follow this and additional works at: https://pdxscholar.library.pdx.edu/honorstheses

Part of the Entrepreneurial and Small Business Operations Commons Let us know how access to this document benefits you.

\section{Recommended Citation}

Chauhan, Prithvi, "A Solution for Sustainable Entrepreneurship: Compostable Consumption Across Industries" (2020). University Honors Theses. Paper 929.

https://doi.org/10.15760/honors.952

This Thesis is brought to you for free and open access. It has been accepted for inclusion in University Honors Theses by an authorized administrator of PDXScholar. Please contact us if we can make this document more accessible: pdxscholar@pdx.edu. 
A Solution for Sustainable Entrepreneurship: Compostable Consumption Across Industries

\author{
Prithvi Chauhan \\ Department of Business Administration, Portland State University \\ HON 403C \\ Dr. Zafrin Rahman, PhD \\ Department of Business Administration, Portland State University \\ Dr. Brenda Glascott, $\mathrm{PhD}$ \\ University Honors College, Portland State University
}

August 14, 2020 


\section{Table of Contents}

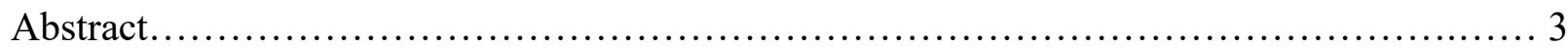

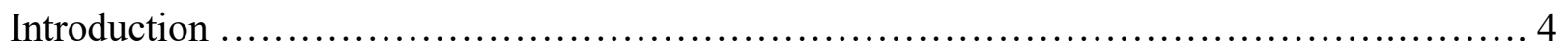

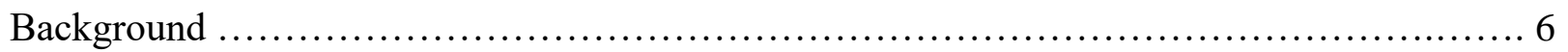

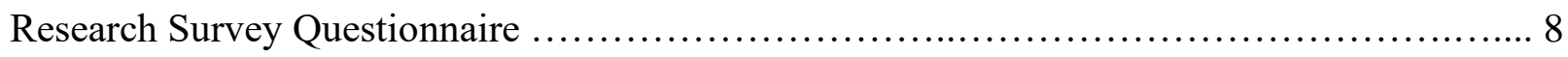

Methods for creating proposed survey......................................... 9

Analyzing Survey Data....................................................... 10

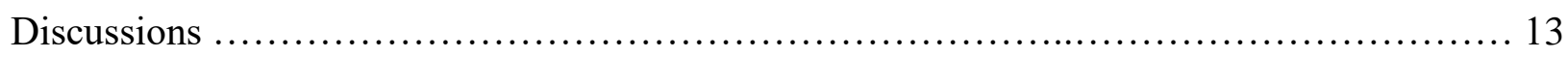

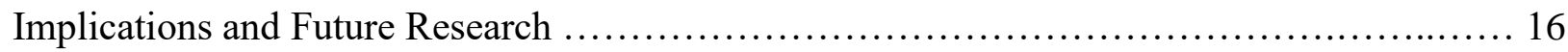

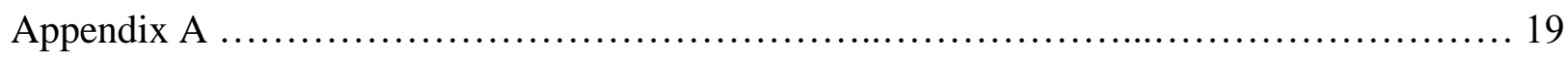

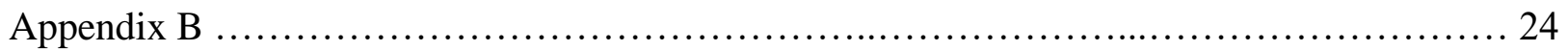




\begin{abstract}
This thesis paper addresses the potentials of a business model for promoting compostable alternatives to single-use plastic products. This thesis paper also proposes a survey to collect data from businesses in Portland, OR to forecast the potential impacts of integrating such a business model. Impacts of this business model for compostable products are hypothesized as best-case, mid-case, and worst-case scenarios of integration within Portland's total market potential. Impacts will also be assessed along the triple bottom line. The triple bottom line is an accounting framework used in sustainable entrepreneurship to measure impact along environmental, social, and economic standards. First, in terms of environmental impact, every compostable product sold is the equivalent to a single-use plastic product not contributing to plastic waste pollution and $\mathrm{CO} 2$ emissions. As a forecasted result of environmental initiative, this study predicts to also make social impacts for participating businesses. As a result of an increase in social ratings from greater perceived corporate social responsibility, this business model also forecasts to bring positive economic impact to participating distributors.
\end{abstract}




\section{Introduction}

This thesis paper addresses the potentials of a business model for promoting compostable alternatives to single-use plastic products. How likely are businesses across industries to adopt compostable solutions and what would be the impact if implemented at scale? This paper also proposes a digital survey to assess the market potential and impact of replacing single-use plastic products with compostable products.

Plastic is always the default material used to make most single-use products including water bottles, pill bottles, and disposable cutlery because it is often the cheapest option. Failure of corporate environmental action across industries has resulted in a larger neglect from the general consumer toward environmental crises taking place worldwide. Corporate failures along social, economic, and ecological standards inspire opportunity for sustainable entrepreneurship (Dean \& McMullen, 2005). Providing a renewable alternative to the highly pollutive industry of single-use plastic products would be implementing a framework and business model for sustainable entrepreneurship.

Sustainable entrepreneurship is, in essence, the realization of sustainable innovations aimed at the mass market and providing benefit to the larger part of society (Schaltegger \& Wagner, 2011). Entrepreneurship literature argues that opportunities for improvement are inherent in existing failures of markets (Dean \& McMullen, 2005). Sustainable entrepreneurship is a socially responsible form of doing business by applying the triple bottom line as a framework for business operations (Majid \& Koe, 2012). The triple bottom line is a sustainability-based accounting method which focuses on people, profit, and the planet (Belz and Binder, 2017). All stakeholders must be addressed under the triple bottom line to ultimately benefit the environment, the general public, and financial stakeholders. This thesis offers a 
proposed digital questionnaire directed at potential business customers to collect data on current plastic distribution habits and business customer interest in environmental initiatives in order to discuss the potential impact, which would be translated into statistics of environmental economics. Environmental economics is an area of economics that studies the financial impact of environmental policies. Environmental economists perform studies to determine the theoretical or empirical effects of environmental policies on the economy (Harrington, 2017).

In the proposed businesses model for compostable products discussed in this paper, every compostable product sold is the equivalent to a single-use plastic product not contributing to plastic waste pollution and $\mathrm{CO} 2$ emissions and impacts will be measured as such. In order to understand the potential for positive environmental effects, this paper will be hypothesizing data to be collected from the digital survey along a best-case, mid-case, and worst-case scenario. Each scenario would be achieved based on how many businesses respond favorably to potentially distributing compostable products through their daily transactions. A worst-case scenario would imply distribution of compostable products by at least $1 \%$ of the local market potential. A midcase scenario would imply adoption by at least $10 \%$ of the market potential, and a best-case scenario would imply adoption by at least $20 \%$ of the market potential.

In addition to calculating potential environmental impact, the survey proposed in this thesis is also intended to gauge corporate cultures of participating businesses. Participating businesses are forecasted to receive positive economic impacts as a result of an increase in social ratings from greater perceived corporate social responsibility. Understanding corporate culture of potential business participants can help create effective marketing and advertising strategies to best propose and integrate new compostable products within already existing businesses across varying industries. 


\section{Background}

Industries like restaurants, cafeterias, coffee shops, dispensaries, and pharmacies are constantly distributing single-use plastic products every day to contribute to plastic waste pollution worldwide. Traditional single-use plastic products such as cups, straws, cutlery, to-go containers, and pill bottles are destined to end up in a landfill or ocean to pollute the natural environment for over 1000 years after disposal. The types of plastics currently being used to make these products come from seven traditional compounds: polyethylene terephthalate (PET), high density polyethylene (HDPE), polyvinyl chloride (PVC), low density polyethylene (LDPE), polypropylene (PP), polystyrene (PS), and polycarbonate (PC). Because all of these forms of plastic are synthesized from natural fossil fuels, their production is also highly dependent on oil companies and fracking industries (Bahraini, 2018). While all these forms of plastic are claimed to be "recyclable," most products used everyday are often not recyclable at all. Due to false advertising from the plastic industry, millions of plastic products are disposed into recycling bins with the full faith that they will be recycled just because the label says it's recyclable. But that's not always the case (Sedeghat, 2018).

In 2017, China placed a ban on plastic waste products. This means that China gained the economic stability to be able to stop having to participate in the plastic waste recycling business, collecting plastic waste to reintegrate recycled material collected from the US, Canada, and the UK into new products, as they did for decades before. As a result of this, waste is now being dumped onto the shores of Malaysia, Indonesia, Vietnam, Thailand, India, and other south Asian countries which do not have the proper facilities to treat or clean (Olson, 2018).

Improper treatment of plastic waste has contributed to the 400 million tons of plastic waste pollution which ends up in oceans and landfills worldwide (Parker, 2018). As plastic takes 
over 1,000 years to decompose, the environment has been facing many harsh consequences of invasive materials contaminating natural environments (Outlet, 2018). The millions of plastic waste products floating through the ocean have caused thousands of deaths to wildlife. Plastic trash is found in the guts of more than 90 percent of the world's sea birds (Polasky, 2019), in the stomachs of more than half of the world's sea turtles (Schuyler \& Wilcox, 2015), and it's even choking the life out of whales (Unger, 2016). At the rate at which plastic is accumulating in the oceans of the planet, it's predicted that, by 2050, the mass of plastic in the world's oceans will exceed the mass of all the fish that live there (Harrington, 2017).

Oil fracking is another large polluting industry which is fueled by demand from the plastic product industry. Plastic products are one of the main products of crude oil pumping and fracking. Oil drilling is the process by which a pointed power tool is sunk into the ground in the hope of producing petroleum for on-site power. Companies like ExxonMobil, Shell, and Saudi Aramco are ramping up output of plastic — which is made from oil and gas, and their byproducts — to hedge against the possibility that a serious global response to climate change might reduce demand for their fuels, analysts say (Gardiner, 2019). In 2016, Shell announced it would be building a multi-billion dollar "cracker" plant — a facility that breaks ethane into ethylene, which is used to make plastic such as polyethylene. Polyethylene is the most common type of plastic used in single-use plastic packaging, the sector that makes up around 40 percent of global production and is the largest and most rapidly growing segment of the plastic economy (Evgeniy, 2019).

Global Warming is a long-term accumulated cost of excessive plastic production and improper disposal systems. First, excessive production of single-use plastic products requires large amounts of energy to process crude oil resulting in thousands of $\mathrm{kg}$ of carbon dioxide 
(CO2) emissions. Excessive $\mathrm{CO} 2$ emissions polluting urban and rural areas significantly harms the air quality while storing greenhouse gasses into the atmosphere to cause a greenhouse effect to raise global temperature (Cassia et. al., 2018). Second, after disposal of single-use plastic products, $80 \%$ of accumulated trash waste is integrated into the recycling economy only to end up incinerated as additional $\mathrm{CO} 2$ emissions or dumped along natural landfills and beaches worldwide.

Unlike plastic products, compostable containers are made from renewable sources which require a much lower melting point than plastic. After disposal, compostable containers will decompose within 10 years in any environment thus preventing plastic waste pollution from entering the natural environment. As each compostable alternative requires 50\% less $\mathrm{CO} 2$ emissions in production and leaves $100 \%$ less harmful waste than paper or plastic alternatives (Howell, 2018), this study will measure ecological effects in terms of both kilograms of CO2 emissions and kilograms of plastic waste for each participating business. This will ultimately reduce carbon footprints to slow the effects of global warming, clean oceans, and save wildlife.

\section{Research Survey Questionnaire}

This is a proposal for a digital survey (Appendix A) which will be disseminated to local businesses to assess their current economic, social, and environmental business habits. The purpose of the proposed digital survey will be to assess the market potential of compostable solutions across different industries as well as to forecast the potential impacts of such a business model. Data on business behaviors collected from this survey will also be used to measure potential impacts of distributing compostable alternatives to plastic products along the triple bottom line. The social, ecological, and economic byproducts of a businesses' operation must be favorable along all three standards in order to effectively achieve sustainable entrepreneurship. 
The questionnaire is designed to collect qualitative data on business owners' social, ecological, and economic habits. This behavioral consumerism study will also reveal businesses' opinions towards eco-friendly products to forecast economic success of compostable solutions.

\section{Methods for Creating Proposed Survey}

This survey was designed to be distributed to businesses with the potential to distribute compostable alternatives to their single-use plastic products. These businesses include restaurants, coffee shops, and cannabis dispensaries. The questions of this survey were designed to assess the current performance and culture of these businesses for the purpose of forecasting potential impacts and creating a marketing and sales strategy to integrate compostable products with current business operations.

More specifically, by asking general demographic questions first (Appendix A, questions 3 and 4), this survey will be able to acknowledge the target consumers more specifically within participating businesses. This information can also be used to influence creative strategies within marketing and design. Similarly, by gauging participating businesses' culture and style (Appendix A; questions 5, 9, and 10), this survey data can influence digital marketing and advertising campaigns to best integrate compostable products to the market. Also, in order to measure the potential for environmental impacts of compostable products being distributed through participating businesses, this survey (Appendix A, question 6) asks for the current quantity of plastic products being distributed. With this survey data, environmental impact can be calculated by preventing said amount of plastic from continuing to pollute to the environment. Finally, this survey (Appendix A, questions 7 and 8) can be used to assess the financial capacity of participating businesses for the purpose of setting a realistic pricing strategy for compostable products. 
In terms of distribution, the digital questionnaire will be shared as a link to consenting participants who will be sought out through regional and national industry association groups within Portland, OR. For example, the Portland Coffee Association can help us reach many local coffee shop managers to participate in a brief study on their social and environmental consumption goals. Through this network of local businesses specific to the coffee shop industry, this study will be able to reach many relevant participants at the same time to maximize access to useful data. Similarly, other industry organizations can be contacted to reach large sample sizes of relevant businesses.

\section{Analyzing Survey Data}

As the survey questionnaire has not yet been disseminated to collect real data from local businesses, potential results for this study have been hypothesized along the total market potential within Portland, OR and within the industries of potential businesses like restaurants, coffee shops, and cannabis dispensaries. Hypothesized results have been summarized in a bestcase, middle-case, and worst case scenario to illustrate the potential implications of this study to prove benefits of a business model for compostable alternatives to single-use plastic products.

In a worst case scenario of implementation, this study will assess the impact of compostable products being distributed from $1 \%$ of Portland-local businesses, or 18 businesses (figure 1). A mid-case scenario would consist of adoption amongst at least $10 \%$ of Portland-local businesses 180 coffee shops. This would approximately equate to $1 \%$ of the regional industry. A mid-case scenario may be achieved by negotiating an exclusive deal with a larger regional chain business such as Dutch Bros. Coffee, Whole Bowl, or Voodoo Doughnuts. The best-case scenario for this study would be acquisition of multiple chain businesses to distribute compostable products for exponentially more sustainable consumption across industries. 
To ensure the standards of sustainable entrepreneurship, hypotheses of impact will be measured along the triple bottom line to prove positive social, political, and economic potential. Ecological performance of a business can be assessed by projecting data from social analyses to estimate potential environmental impact in a worst, mid, and best-case scenario. Ecological impact will be measured in $\mathrm{kg}$ of $\mathrm{CO} 2$ emissions prevented along both production and disposal of compostable alternatives. As the melting point of bioplastic alternatives are much lower than traditional PET plastic material, much fewer $\mathrm{CO} 2$ emissions are required during production of compostable containers. After disposal, compostable containers will decompose within 10 years in any environment thus preventing plastic waste pollution from entering the natural environment.

\section{Figure 1}

\section{Market Potential within Portland, OR}

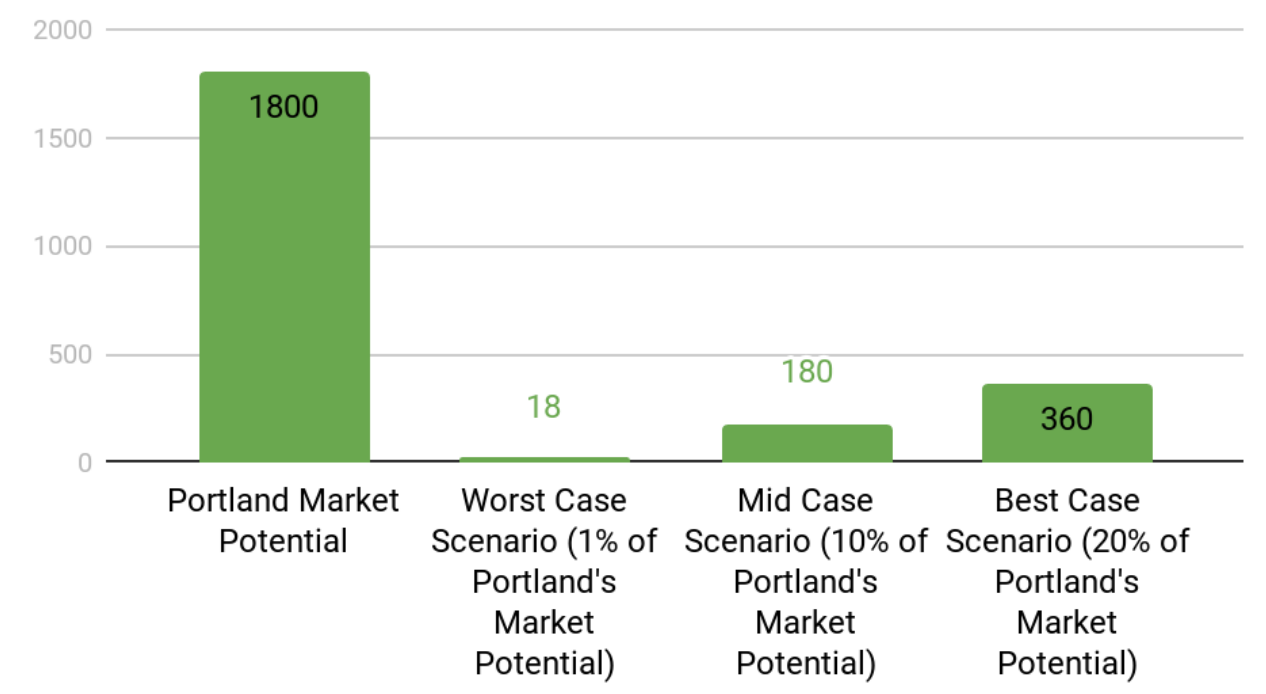

Participating

Businesses

Note. Total Portland market share includes total revenue potential across industries within the entire Portland metro area including all coffee shops, restaurants, and dispensaries

(Calculations in Appendix). 


\section{Figure 2}

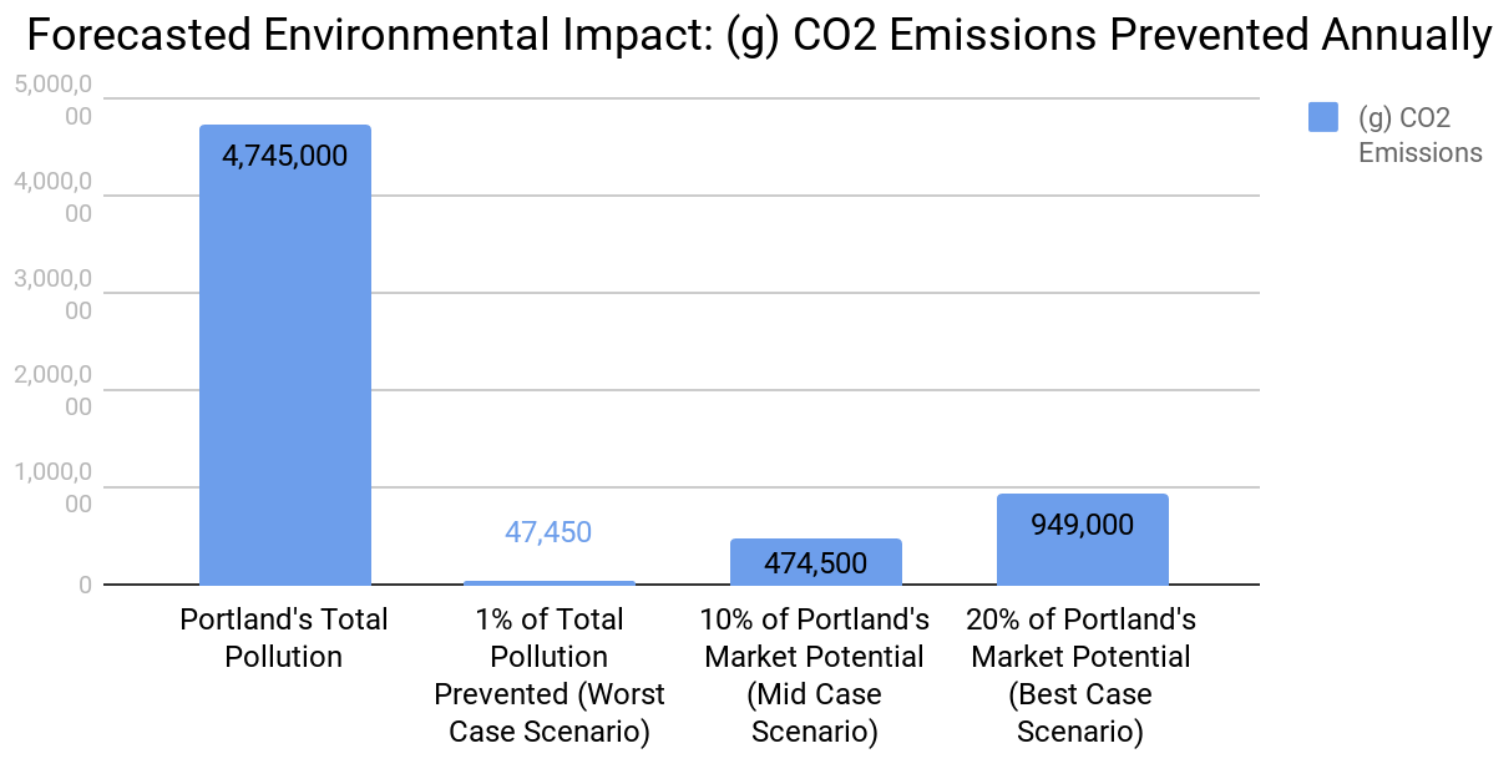

Note. This sample is specific to only businesses in the Portland metro area which are involved in the distribution of single-use plastic product distribution. Total pollution recorded for each scenario is anticipated to be achieved by preventing $50 \%$ of CO2 emissions (Calculations in Appendix). 


\section{Figure 3}

\section{Forecasted Environmental Impact: (g) Plastic Waste Prevented Annually}

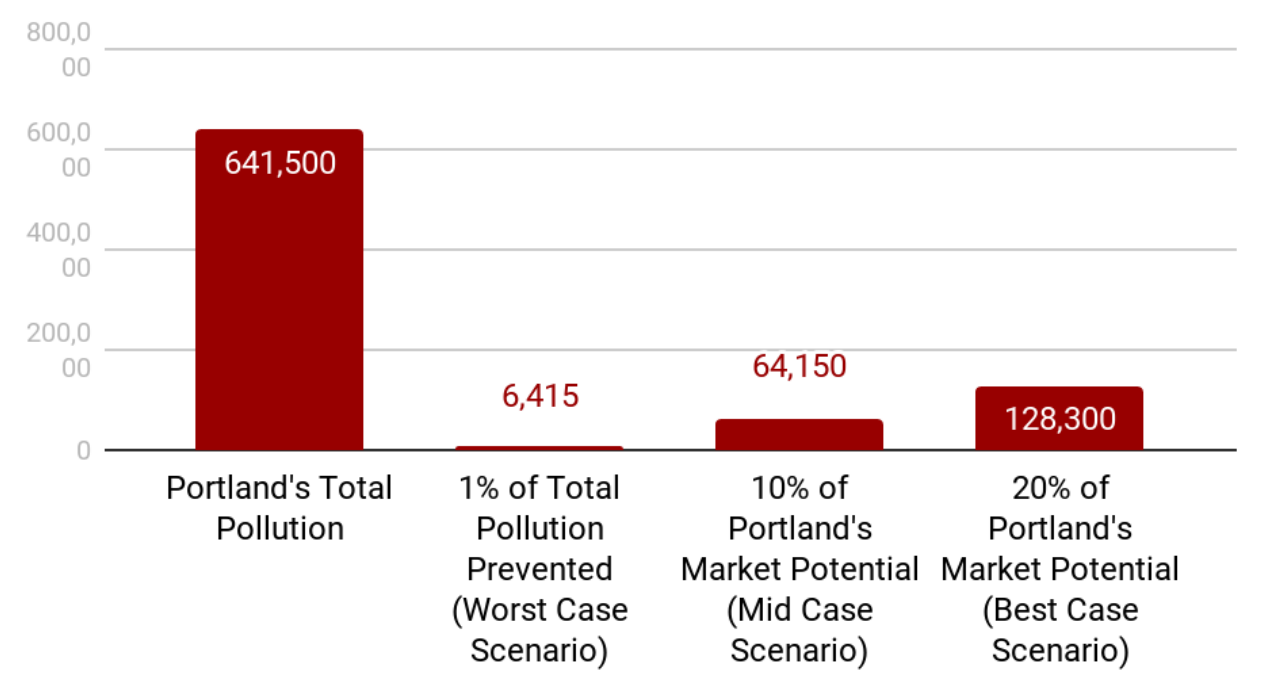

Note. This sample is again specific to only businesses in the Portland metro area which are involved in the distribution of single-use plastic product distribution. Total pollution recorded for each scenario is anticipated to be achieved by preventing $100 \%$ of plastic or paper litter after single-use and disposal (Calculations in Appendix).

\section{Discussion}

This survey has the potential to bring much valuable insight into businesses aiming to market compostable alternatives to single-use plastic products. The insights to be inferred from the data collected through this survey will help businesses devise an effective marketing and pricing strategy. Data on sales from potential customers will also be translated into environmental projections (Figures 1,2, and 3) to forecast positive environmental impacts to also 
help persuade potential participating businesses to invest in compostable products for ecological reasons as well.

As determined from the hypothesized data scenarios, if actually implemented by even just $1 \%$ of target businesses (18 businesses), the compostable product business model has potential to prevent $47,450 \mathrm{~kg}$ of $\mathrm{CO} 2$ emissions and $6,415 \mathrm{~kg}$ of plastic waste (Figures 1 and 2). Through social promotion, even one participating business also harnesses the potential to lead their local community toward a larger environmental movement to encourage other businesses to also adopt more eco-friendly solutions. Similarly, a mid-case scenario would involve successfully distributing compostable products through $10 \%$ of Portland's restaurants, coffee shops, cafeterias, etc. The environmental impact of sustainable consumption scales across $10 \%$ of all Portland businesses would forecast the successful prevention of 474,500 kilograms of CO2 emissions and $64,150 \mathrm{~kg}$ of plastic waste. In a best-case scenario, by distributing compostable products across $20 \%$ of all Portland businesses, this study forecasts 949,000 kilograms of CO2 emissions and 128,300 kg of plastic waste prevented (Figures 1 and 2).

While all three of these scenarios are only representing a small total market potential, this is only a beach-head market estimated to be acquired in the first year of commercialization. Through digital marketing and cross-promotion campaigns, this study further forecast to introduce this new innovation to more exponentially more businesses with time.

\section{Implications and future research}

If the distribution of compostable products was adopted at scale, benefits would immediately contribute to positive ecological, economic, and social repercussions. The environment will be most directly impacted by the prevention of pollution from plastic production and waste. This recycling ecosystem will also impact the internal economies of 
participating businesses by obtaining a relatively cheaper eco-friendly alternative to traditional plastic products. Other economic benefits are also anticipated to come from improved social ratings. Marketing eco-friendly solutions can help participating businesses improve the brand's social image and experiential rating. Bringing environmental solutions to consumers can also raise awareness of general environmental determinants caused by unsustainable competitors. 


\section{References}

Bahraini (2008, July 17). 7 Types of Plastic that You Need to Know. Waste 4 Change. https://waste4change.com/7-types-plastic-need-know/

Belz, F. M., and Binder, J. K. (2017) Sustainable Entrepreneurship: A Convergent Process Model. Bus. Strat. Env., 26, 1- 17. doi: 10.1002/bse.1887.

Cassia, R., Nocioni, M., Correa-Aragunde, N., \& Lamattina, L. (2018). Climate Change and the Impact of Greenhouse Gasses: $\mathrm{CO}_{2}$ and NO, Friends and Foes of Plant Oxidative Stress. Frontiers in plant science, 9, 273. https://doi.org/10.3389/fpls.2018.00273

Dean \& McMullen (2007). Toward a theory of sustainable entrepreneurship: Reducing environmental degradation through entrepreneurial action. Journal of Business Venturing, 22(1), 50 - 76

Gardiner (2019, December 19). The Plastics Pipeline: A Surge of New Production Is on the Way. Yale School of the Environment. https://e360.yale.edu/features/the-plastics-pipeline-asurge-of-new-production-is-on-the-way

Harrington, R. (2017, January 26). By 2050, the Oceans could Have More Plastic than Fish. Business Insider. https://www.businessinsider.com/plastic-in-ocean-outweighs-fishevidence-report-2017-1

Howell, L., Skully, R. (2018). It doesn’t stack up...How disposables compare to reusables. Hope 
Solutions. http://www.powerful-thinking.org.uk/site/wp-

content/uploads/5ae32a2a8cb7533f8f110742_Reusable-Cups-Factsheet.pdf

Majid, I.A., \& Koe, W. (2012). Sustainable Entrepreneurship (SE): A Revised Model Based on Triple Bottom Line (TBL). International Journal of Academic Research in Business and Social Sciences 2 (6), 293-310

Olson, R. (2018, November 16). China's ban on trash imports shifts the waste crisis to Southeast Asia. National Geographic. https://www.nationalgeographic.com/environment/2018/11/china-ban-plastic-trashimports-shifts-waste-crisis-southeast-asia-malaysial

Parker, Laura (2018, December 20). A whopping 91\% of plastic isn't recycled. National Geographic. https://www.nationalgeographic.com/news/2017/07/plastic-producedrecycling-waste-ocean-trash-debris-environment/

Polasky, S., Kling, C. L., Levin, S. A., Carpenter, S. R., Daily, G. C., Ehrlich, P. R., Heal, G. M., \& Lubchenco, J. (2019). Role of economics in analyzing the environment and sustainable development. Proceedings of the National Academy of Sciences of the United States of America, 116(12), 5233-5238. https://doi.org/10.1073/pnas.1901616116

Sax, Sarah (2019, May 24). The Hidden Relationship between the Plastics Industry and 
Fracking in the US. GreenBiz. https://www.greenbiz.com/article/hidden-relationshipbetween-plastics-industry-and-fracking-us

Schaltegger, S. and Wagner, M. (2011), Sustainable entrepreneurship and sustainability innovation: categories and interactions. Bus. Strat. Env., 20, 222-237.

Schuyler, Q. A., Wilcox, C., Townsend, K. A., Wedemeyer-Strombel, K. R., Balazs, G., Sebille, E. van, \& Hardesty, B. D. (2015). Risk analysis reveals global hotspots for marine debris ingestion by sea turtles. Glob Chang Biol. 22(2), 567-576. doi:10.1111/gcb.13078

Sedaghat (2018, April 4). 7 Things You Didn't Know About Plastic (and Recycling). National Geographic. https://blog.nationalgeographic.org/2018/04/04/7-things-you-didnt-knowabout-plastic-and-recycling/

Unger, B., Rebolledo, E., Deaville, R., Gröne, A., IJsseldijk, L. L., Leopold, M. F., Siebert, U., Spitz, J., Wohlsein, P., \& Herr, H. (2016). Large amounts of marine debris found in sperm whales stranded along the North Sea coast in early 2016. Marine pollution bulletin, 112(1-2), 134-141.

Wilcox, C. , Sebille, E.V. , \& Hardesty, B.D. (2015). Threat of Plastic Pollution to Seabirds is Global, Pervasive, and Increasing. Proceedings of the National Academy of Sciences, $112(38), 11899-11904$ 


\section{Appendix A}

Digital Survey Questionnaire to be disseminated to business owners across industries:

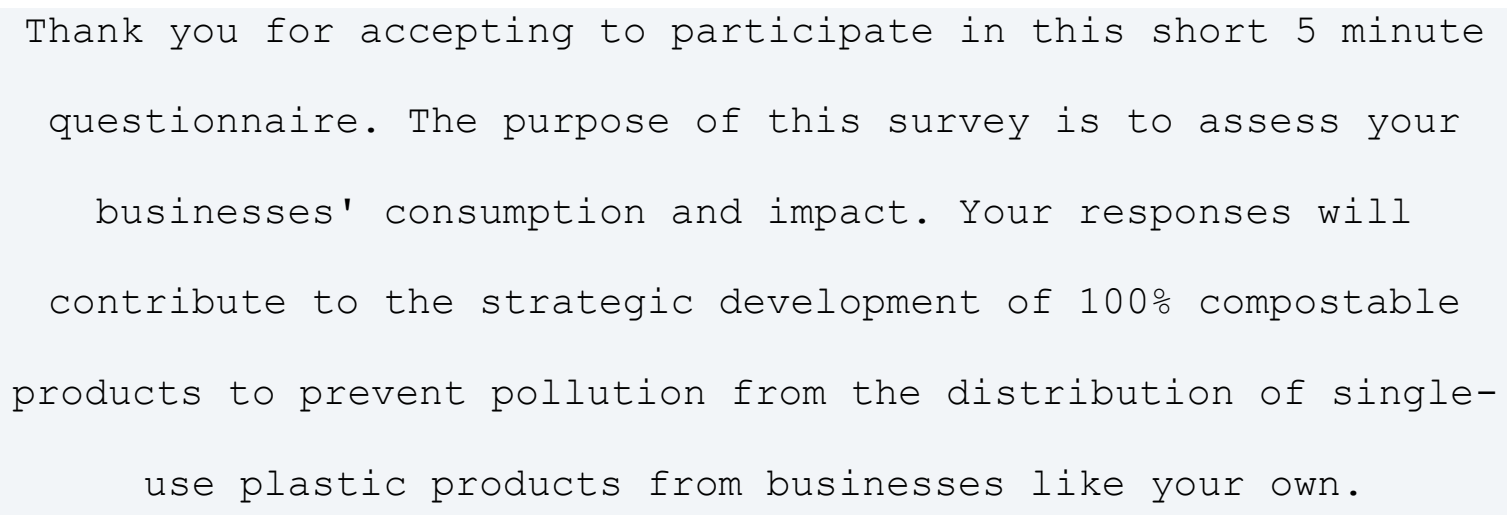

1. What is the name of your business?

2. Which industry does your business exist within?

- Cafés

- Restaurants

- Cafeterias

- Pharmacies

- Dispensaries (Cannabis)

- Other

3. Select the average age range of your customers:

- $0-25$

- 26-35

- $36-45$

- 46-55

- $55+$ 
4. Select the average annual income range of your customers:

- $\$ 0-\$ 35,000$

- $\$ 36,000-\$ 55,000$

- $\$ 56,000-\$ 75,000$

- $\$ 76,000-\$ 100,000$

- $\$ 101,000-\$ 130,000$

- $\$ 131,000+$

5. How important are the following to your business?

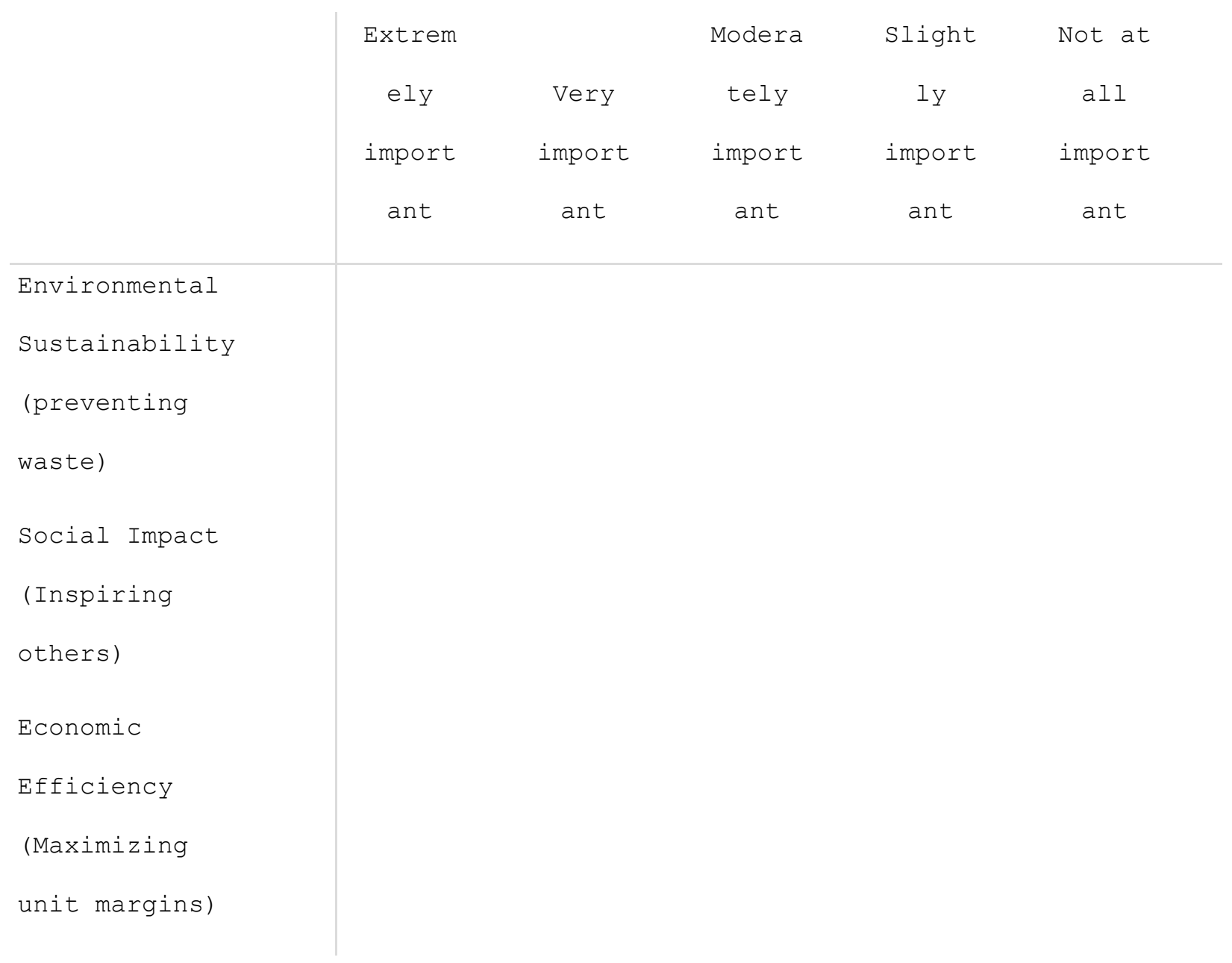


6. Approximately how many units of single-use plastic products do you distribute each day (i.e. cups/lids, utensils, to-go boxes, pill bottles, etc.) ? Select all that apply:

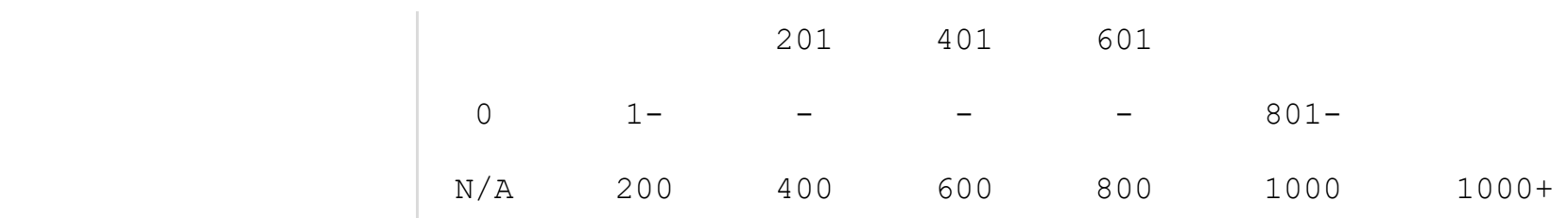

Cups \& Lids

Utensils and

Straws

To-go boxes

Small

containers

Other

Other

7. Approximately how much do you pay for your single-use plastic products (i.e. cups/lids, utensils, to-go boxes, pill bottles, containers, etc.) each month?

- $\$ 0-\$ 200$

- $\$ 201-400$

- $\$ 401-600$

- $\$ 601-\$ 800$

- $\$ 800-\$ 1000$

- Other 
8. Approximately how much more money are you willing to pay for a $100 \%$ compostable alternative to single-use plastic products?

- $100 \%$ more

- $75 \%$ more

- $50 \%$ more

- $25 \%$ more

- $10 \%$ more

- $5 \frac{\circ}{0}$ more

- 0\% more. I would not pay more for compostable alternatives.

9. Explain how you would like your business to be perceived by the public (Select all that apply):

- Classic

- Modern

- Sociable

- Fast-paced

- Formal

- Informal

- Socially or politically active

- Laid-back

10. How active is your brand's presence on social media platforms?

- Strongly active

- Active

- Somewhat active 
- Not active in a long while

- We don't have any digital media platforms

Thank you for your participation in this study! 


\section{Appendix B}

\section{Calculations for Figures 1:}

Portland Market Potential =

\# of Restaurants in Portland + \# of Coffee Shops in Portland + \# of Dispensaries in Portland

$=1000$ restaurants +500 coffee shops +300 dispensaries $=1800$ potential business

Worst-Case Scenario: Portland Market Potential * 1\% = Total \# of businesses participating

$=18$ participating businesses

Mid-Case Scenario: Portland Market Potential * 10\% = Total \# of businesses participating

$=180$ participating businesses

Best-Case Scenario: Portland Market Potential * 20\% = Total \# of businesses participating

$=360$ participating businesses

(Howell, 2018)

\section{Calculations for Figure 2:}

Portland's Total Market Pollution from single-use plastic products (in $\mathrm{g}$ of $\mathrm{CO} 2$ emissions) $=$ (CO2 emissions from a plastic cup * Total \# of units sold each day * Total \# of coffee shops in Portland *365 days) +

(CO2 emissions from a to-go container * Total \# of units sold each day * Total \# of restaurants in Portland * 365 days) +

(CO2 emissions from a dispensary container * Total \# of units sold each day * Total \# of dispensaries in Portland * 365 days)

$=[40 \mathrm{~g} * 250$ units $* 500$ coffee shops $* 365$ days $]+[80 \mathrm{~g} * 100$ units $* 1000$ restaurants $* 365$ days $]+[20 \mathrm{~g} * 200$ units $* 300$ dispensaries $* 365$ days $]=4,745,000 \mathrm{~kg}$ of CO2 emissions 
Worst-Case Scenario: Portland's Total Annual Market Pollution $* 1 \%=47,450 \mathrm{~kg}$ of CO2 emissions

Mid-Case Scenario: Portland's Total Annual Market Pollution * 10\%=474,500 kg of CO2 emissions

Best-Case Scenario: Portland's Total Annual Market Pollution * 20\%=949,000 kg of CO2 emissions

\section{Calculation for Figure 3:}

Portland's Total Market Pollution from single-use plastic products (in grams of plastic waste) $=$ (Total grams of plastic waste material from a coffee cup * Total \# of units sold each day * Total \# of coffee shops in Portland) +

(Total grams of plastic waste material from a to-go container * Total \# of units sold each day * Total \# of restaurants in Portland) +

(Total grams of plastic waste material from a dispensary container * Total \# of units sold each day * Total \# of dispensaries in Portland)

$=[20 \mathrm{~g} * 250$ units $* 500$ coffee shops $* 365$ days $]+[40 \mathrm{~g} * 100$ units $* 1000$ restaurants $* 365$ days $]+[10 \mathrm{~g} * 200$ units $* 300$ dispensaries $* 365$ days $]=641,500 \mathrm{~kg}$ of plastic waste Worst-case scenario: Portland's total market plastic waste pollution $* 1 \%=6,415 \mathrm{~kg}$ of plastic waste prevented

Mid-case scenario: Portland's total market plastic waste pollution $* 10 \%=64,150 \mathrm{~kg}$ of plastic waste prevented

Best-case scenario: Portland's total market plastic waste pollution $* 20 \%=128,300 \mathrm{~kg}$ of plastic waste prevented 